\title{
The Prevalence and Risk Factors of Type 2 Diabetes Mellitus (DMT2) in a Semi-Urban Saudi Population
}

\author{
Mohammed Abdullah Al Mansour \\ Department of Family Medicine, College of Medicine, Majmaah University, Almajmaah 11952, Saudi Arabia; \\ m.aalmansour@mu.edu.sa
}

Received: 5 November 2019; Accepted: 3 December 2019; Published: 18 December 2019

check for updates

\begin{abstract}
Background: Diabetes mellitus is a common health problem in Saudi Arabia, causing a huge burden for individuals, families, and communities. The objectives of the current study were to determine the prevalence and risk factors of type 2 diabetes mellitus among a semi-urban population of Saudi Arabia. (2) Research methods: The research design was cross-sectional, and the research was conducted in five primary health care centers (PHCC) in Majmaah, Saudi Arabia. The sample size was calculated as 353. A pre-tested questionnaire was used to collect data after obtaining ethical approval. Blood samples were taken to assess glucose levels and other variables. SPSS version 21 was used to analyze data. (3) Results: The prevalence of type 2 diabetes mellitus was $34.6 \%$. The disease was more prevalent among the older respondents compared with the younger age groups $(44.6 \%$ versus $15.6 \%)$. We found that females acquire the disease at a slightly higher rate than males $(34.9 \%$ versus $34.2 \%)$, but this difference is not statistically significant. The sociodemographic risk factors of the disease were as follows: old age (44\%), business and private occupation (38.5\%), divorced or widowed $(56.3 \%)$, and low income $(42.4 \%)$. The health behaviors factors were as follows: overweight or obese status (42.3\%), high triglycerides (TG) (43.4\%), low high-density lipoprotein (HDL) (37.3\%), and high total cholesterol $(23.7 \%)$. There was a statistically significant difference in these risk factors between patients with and without diabetes. (4) Conclusion: The prevalence of type 2 diabetes mellitus among the semi-urban population of Saudi Arabia is high. The disease is more prevalent among elderly respondents and is associated with obesity, high TG, low HDL, and high total cholesterol.
\end{abstract}

Keywords: diabetes mellitus; prevalence; risk factors; semi-urban population

\section{Introduction}

Diabetes mellitus is a multifactorial disease of considerable heterogeneity [1-3]. The disease is the most common chronic endocrine disorder, affecting an estimated $5 \%-10 \%$ of adults worldwide $[4,5]$. Predictions based on many studies have indicated a growing increase of diabetes mellitus, particularly in developing countries. It is predicted that between 2010 and 2030, developed and developing countries will see a $20 \%$ and $69 \%$ increase, respectively, in the number of adults with diabetes [6]. The prevalence of diabetes among those aged 20-79 years may increase to $7.7 \%$, constituting 439 million by 2030 [7]. Many studies have shown that lifestyle modifications are effective in preventing obesity and diabetes in high-risk adults with impaired glucose tolerance [8].

Globally, the east Mediterranean region has the second highest prevalence of diabetes in terms of population. According to the World Health Organization (WHO), almost a quarter of the region's population has diabetes of one form or another [2].

Data from the Gulf revealed high prevalence rates of type 2 diabetes mellitus. The reported prevalence rates were $25.7 \%, 16.1 \%$, and $21 \%$ in Bahrain, Oman, and Kuwait, respectively [8-10].

The prevalence of diabetes mellitus is high in the Saudi population and represents a major public health concern; the number of diabetic patients has steadily increased over the last several decades [11]. 
The prevalence of diabetes mellitus in Saudi Arabia was found to be $31.6 \%$ of the general population, $14.1 \%$ of the working population, $34.6 \%$ of males, and $27.6 \%$ of females $[4,12,13]$. Diabetes mellitus has a high economic impact; the indirect national financial burden is likely to exceed 0.87 billion USD, and patients with diabetes, on average, incur healthcare costs that are almost ten times higher ( $\$ 3686 \mathrm{vs}$. \$380) than those without diabetes [14,15].

The objective of the current study was to determine the prevalence and risk factors of type 2 diabetes mellitus in a semi-urban Saudi population.

\section{Patients and Methods}

The cross-sectional study was conducted in Majmaah City, Riyadh Province, Saudi Arabia [16]. Patients of both sexes who attended primary health care centers (PHCCs) during the study period were enrolled in the study. Children, non-Saudi patients, and those who were nonresidents of Majmaah were excluded from the study. At the level of the PHCC, stratified random sampling was employed; five out of the 11 PHCCs in the city were selected. Stratification was based on the patients' load. The selection of the respondents at the level of PHCCs was performed by systematic sampling, and the interval was counted by dividing the estimated average number of patients attending the center every day by the number of the sample agreed to be taken in the same day.

A total of 384 patients were enrolled in the study, of which 353 completed the study. The sample size was calculated using the level of precision formula $(n=\mathrm{Z} 2 \times p(1-p) / \mathrm{d} 2)$, where $n$ is the sample size, $\mathrm{z}$ is the standard error associated with the chosen level of confidence (1.96), $p$ is estimated prevalence (0.50), $\mathrm{q}$ is $1-p(0.50)$, and $\mathrm{d}$ is the acceptable error (0.05). The patients were interviewed with a structured questionnaire. Patients' demographic data, medical history, and social and lifestyle history were documented. Blood pressure was taken in a single visit by an electronic sphygmomanometer. Joint National Committee 8 (JNC 8) criteria were taken as standard in the measurements [17]. High blood pressure readings were defined as $\geq 140 / 90 \mathrm{~mm}$ of $\mathrm{Hg}$. Height and weight were measured using calibrated portable scales and a steel tape measure, respectively. Patients were weighed with light clothes and with shoes off. The height of patients was measured without shoes. The formula weight $(\mathrm{kg}) /$ height $(\mathrm{m}) 2$ was used to calculate the BMI of the respondents. Respondents who scored a BMI of 25-29.9 were considered overweight, and those who had a BMI of 30 or more were considered obese [18].

Blood samples were extracted immediately if the patient was fasting or on the following day if not in order to test fasting blood glucose and HBA1c. Respondents who met the ADA 2014 criteria of diabetes mellitus were diagnosed as patients with diabetes [19]. Blood samples to test triglycerides (TG), total cholesterol, high-density lipoprotein (HDL), and low-density lipoprotein (LDL) were also taken from all respondents. The cut-off levels were used according to the suggestions of the National Cholesterol Education Program Adult Treatment Panel III [20].

The data were entered and analyzed using SPSS for Windows, version 21 (SPSS, Chicago, IL, USA). Descriptive statistics were used, and comparisons between qualitative data were made using chi-square tests to gauge significance. A p value of less than 0.05 was considered statistically significant.

Ethical approval was obtained from the Majmaah University Ethics Committee. All the respondents gave their written informed consent, all data were kept confidential, and the right of the patients to withdraw from the study was respected throughout.

\section{Results}

The results show that 122 (34.6\%) of the respondents had diabetes mellitus, as shown in Figure 1. 


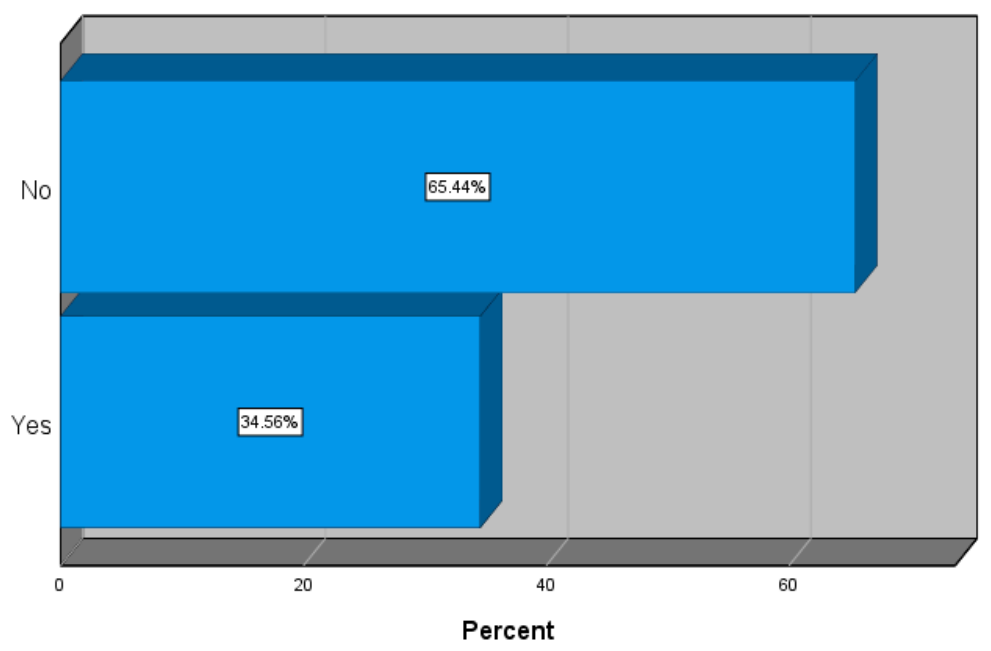

Figure 1. Prevalence of type 2 diabetes mellitus (DMT2).

Table 1 shows the relationship between diabetes mellitus and various sociodemographic characteristics. Nineteen (15.6\%) of the respondents younger than 40 years of age and $103(44.6 \%)$ of those at least 40 years old had diabetes mellitus $(p<0.001)$. A total of $56(34.2 \%)$ and $66(34.9 \%)$ of males and females had the disease, respectively. Diabetes mellitus rates among business or private persons, government employees, housewives, and students were $38.5 \%, 32 \%, 10.3 \%$, and $31.9 \%$, respectively. Five (10.4\%) of the single, $99(36.3 \%)$ of the married, and $18(56.3 \%)$ of the divorced or widowed respondents had type 2 diabetes mellitus $(p<0.001)$. The disease in the low-, moderate-, and high-income groups constituted $42.4 \%, 29.0 \%$, and $26.1 \%$.

Table 1. The relationship between DMT2 and sociodemographic characteristics $(n=122)$.

\begin{tabular}{|c|c|c|c|c|}
\hline \multirow{2}{*}{ Sociodemographic Factors } & \multicolumn{2}{|c|}{ Diabetes Mellitus } & \multirow{2}{*}{ Total } & \multirow{2}{*}{$p$} \\
\hline & Present & Absent & & \\
\hline \multicolumn{5}{|l|}{ Age/years: } \\
\hline Less than 40 & $19(15.6 \%)$ & $103(84.4 \%)$ & $122(34.6 \%)$ & \multirow[t]{2}{*}{$<0.001$} \\
\hline 40 and more & $103(44.6 \%)$ & $128(55.4 \%)$ & $231(65.4 \%)$ & \\
\hline \multicolumn{5}{|l|}{ Gender: } \\
\hline Male & $56(34.2 \%)$ & $108(65.8 \%)$ & $164(46.5 \%)$ & \multirow{2}{*}{0.9164} \\
\hline Female & $66(34.9 \%)$ & $123(65.1 \%)$ & $189(53.5 \%)$ & \\
\hline \multicolumn{5}{|l|}{ Occupation: } \\
\hline Business or private & $57(38.5 \%)$ & $91(61.5 \%)$ & 148 (41.9\%) & \multirow{5}{*}{$<0.00$} \\
\hline Government employees & $41(32 \%)$ & $87(68 \%)$ & $128(36.3 \%)$ & \\
\hline Housewife & $3(10.3 \%)$ & $26(89.7 \%)$ & $89(8.2 \%)$ & \\
\hline Students & $7(31.9 \%)$ & $15(68.1 \%)$ & $22(6.2 \%)$ & \\
\hline Others & $14(53.8 \%)$ & $12(46.2 \%)$ & $26(7.4 \%)$ & \\
\hline \multicolumn{5}{|l|}{ Marital status: } \\
\hline Single & $5(10.4 \%)$ & $43(89.6 \%)$ & $48(13.6 \%)$ & \multirow{3}{*}{$<0.001$} \\
\hline Married & $99(36.3 \%)$ & $174(63.7)$ & $273(77.3 \%)$ & \\
\hline Divorced/widow & $18(56.3 \%)$ & $14(43.7 \%)$ & $32(9.0 \%)$ & \\
\hline \multicolumn{5}{|l|}{ Monthly income (SR): } \\
\hline Low $(<5000)$ & $70(42.4 \%)$ & $95(57.6 \%)$ & $165(46.7 \%)$ & \multirow{3}{*}{0.032} \\
\hline Moderate $(5000-10,000)$ & $29(29 \%)$ & $71(71 \%)$ & $100(28.3 \%)$ & \\
\hline High $(>10,000)$ & $23(26.1 \%)$ & $65(73.9 \%)$ & $88(25.0 \%)$ & \\
\hline
\end{tabular}

Table 2 shows the risk factors of diabetes mellitus. Performing regular physical activities, smoking tobacco, consuming fatty foods, high LDL, and high blood pressure were statistically insignificant factors in patients with diabetes. On the other hand, seven (13.2\%) of the normal or underweight 
respondents had type 2 diabetes mellitus compared to 115 (42.3\%) of the overweight or obese patients $(p<0.001)$. Triglyceride levels were found to be influential, as $76(32.5 \%)$ patients with desirable or borderline TG had type 2 diabetes mellitus, compared with $46(43.4 \%)$ patients with high levels of triglycerides $(p<0.004)$.

Table 2. Risk factors of DMT2.

\begin{tabular}{|c|c|c|c|c|}
\hline \multirow{2}{*}{ Risk Factor } & \multicolumn{2}{|c|}{ Diabetes Mellitus } & \multirow{2}{*}{ Total } & \multirow{2}{*}{$p$} \\
\hline & Present & Absent & & \\
\hline \multicolumn{5}{|c|}{ Perform regular physical activity: } \\
\hline Yes & $28(31.1 \%)$ & $62(68.9 \%)$ & $90(25.5 \%)$ & \multirow{3}{*}{0.490} \\
\hline No & $94(35.7 \%)$ & $169(64.3 \%)$ & $263(74.5 \%)$ & \\
\hline Total & $122(34.6 \%)$ & $231(65.4 \%)$ & $353(100 \%)$ & \\
\hline \multicolumn{5}{|c|}{ Consumption of fatty foods: } \\
\hline Yes & $108(35.6 \%)$ & $195(64.4 \%)$ & $303(85.8 \%)$ & \multirow{3}{*}{0.248} \\
\hline No & $14(28.0 \%)$ & $36(72.0 \%)$ & $50(14.2 \%$ & \\
\hline Total & $122(34.6 \%)$ & $231(65.4 \%)$ & $353(100 \%)$ & \\
\hline \multicolumn{5}{|l|}{ Tobacco smoking: } \\
\hline Yes & $9(25.7 \%)$ & $26(74.3 \%)$ & $35(9.9 \%)$ & \multirow{3}{*}{0.132} \\
\hline No & $113(35.5 \%)$ & $205(64.5 \%)$ & $318(90.1 \%)$ & \\
\hline Total & $122(34.6 \%)$ & $231(56.4 \%)$ & $353(100 \%)$ & \\
\hline \multicolumn{5}{|l|}{ BMI: } \\
\hline Underweight/normal & $7(13.2 \%)$ & $46(86.8 \%)$ & $53(15.0 \%)$ & \multirow{3}{*}{0.013} \\
\hline Overweight/obese & $115(42.3 \%)$ & $185(57.7 \%)$ & $300(22.1 \%)$ & \\
\hline Total & $122(34.6 \%)$ & $231(65.4 \%)$ & $353(100 \%)$ & \\
\hline \multicolumn{5}{|c|}{ Low-density lipoprotein (LDL): } \\
\hline Optimum/Border line & $95(34.8 \%)$ & $178(65.2 \%)$ & $109(85.4 \%)$ & \multirow{3}{*}{0.869} \\
\hline High & $27(33.7 \%)$ & $53(66.3 \%)$ & $80(22.6 \%)$ & \\
\hline Total & $122(34.6 \%)$ & $231(65.4 \%)$ & $353(100 \%)$ & \\
\hline \multicolumn{5}{|l|}{ Triglycerides: } \\
\hline Desirable/borderline & $76(32.5 \%)$ & $158(67.5 \%)$ & $234(66.3 \%)$ & \multirow{3}{*}{0.004} \\
\hline High & $46(43.4 \%)$ & $73(56.6 \%)$ & $119(33.7 \%)$ & \\
\hline Total & $122(34.6 \%)$ & $231(65.4 \%)$ & $353(100 \%)$ & \\
\hline \multicolumn{5}{|l|}{ Total cholesterol: } \\
\hline Desirable & $113(35.9 \%)$ & $202(64.1 \%)$ & $315(89.2 \%)$ & \multirow{3}{*}{0.016} \\
\hline High & $9(23.7 \%)$ & $29(76.3 \%)$ & $38(10.8 \%)$ & \\
\hline Total & $122(34.6 \%)$ & $231(65.4 \%)$ & $353(100 \%)$ & \\
\hline \multicolumn{5}{|c|}{ High-density lipoprotein (HDL): } \\
\hline Low/average & $101(37.3 \%)$ & $170(62.7 \%)$ & $271(76.8 \%)$ & \multirow{3}{*}{0.012} \\
\hline High & $21(25.6 \%)$ & $61(74.4 \%)$ & $82(23.2 \%)$ & \\
\hline Total & $122(34.6 \%)$ & $231(65.4 \%)$ & $353(100 \%)$ & \\
\hline \multicolumn{5}{|l|}{ Hypertension: } \\
\hline Normal & $111(33.9 \%)$ & $216(66.1 \%)$ & 327 (92.6\%) & \multirow{3}{*}{0.221} \\
\hline High & $11(42.3 \%)$ & $15(57.7 \%)$ & $26(7.4 \%)$ & \\
\hline Total & $122(34.6 \%)$ & $231(65.4 \%)$ & $353(100 \%)$ & \\
\hline
\end{tabular}

Total cholesterol levels were also found to be significant, as the results showed that $113(35.9 \%)$ patients with desirable total cholesterol levels and nine (23.7\%) patients with high levels had type 2 diabetes mellitus $(p<0.016)$. A total of $101(37.3 \%)$ patients with low/average HDL and $21(25.6 \%)$ patients with HDL had DMT2 $(p<0.012)$.

The logistic regression results are presented in Table 3. The risk of getting diabetes lowered as respondents' ages decreased (adjusted odds ratio $(\mathrm{AOR})=0.536, p<0.001)$. The rest of the factors were not significant $(p>0.05)$. Patients who had DMT2 had significantly high levels of triglycerides 
$(\mathrm{AOR}=0.654, p=0.004)$ and high BMI $(\mathrm{AOR}=0.667, p=0.013)$. These patients with diabetes had significantly low levels of HDL (AOR $=1.540, p=0.012)$ and total cholesterol $(\mathrm{AOR}=2.109, p=0.016)$.

Table 3. Logistic regression.

\begin{tabular}{|c|c|c|c|c|}
\hline \multicolumn{5}{|c|}{ Sociodemographic Characteristics } \\
\hline \multirow{2}{*}{ Item } & \multirow{2}{*}{ AOR } & \multirow{2}{*}{$p$} & \multicolumn{2}{|c|}{$95 \%$ CI for AOR } \\
\hline & & & Lower & Upper \\
\hline Age & 0.536 & $<0.001 *$ & 0.425 & 0.675 \\
\hline Gender & 1.152 & 0.609 & 0.669 & 1.983 \\
\hline Occupation & 0.208 & 0.999 & 0.880 & 1.137 \\
\hline Monthly income & 0.890 & 0.214 & 0.897 & 1.629 \\
\hline \multicolumn{5}{|c|}{ Risk Factors } \\
\hline \multirow{2}{*}{ Item } & \multirow{2}{*}{ AOR } & \multirow{2}{*}{$p$} & \multicolumn{2}{|c|}{$95 \% \mathrm{CI}$ for AOR } \\
\hline & & & Lower & Upper \\
\hline Regular physical exercise & 0.768 & 0.338 & 0.448 & 0.675 \\
\hline Fatty food & 1.205 & 0.596 & 0.604 & 2.402 \\
\hline smoking & 0.516 & 0.122 & 0.223 & 1.195 \\
\hline BMI & 0.667 & $0.013 *$ & 0.485 & 0.918 \\
\hline LDL & 0.906 & 0.329 & 0.742 & 1.105 \\
\hline Total cholesterol & 2.109 & $0.016^{*}$ & 1.152 & 3.861 \\
\hline HDL & 1.540 & 0.012 * & 1.098 & 2.161 \\
\hline Triglyceride & 0.654 & 0.004 * & 0.491 & 0.871 \\
\hline
\end{tabular}

* Significant at $5 \%$ level of significance; AOR: Adjusted odds ratio.

\section{Discussion}

The data were collected from 353 patients who attended a PHCC in Majmaah, Saudi Arabia. According to our findings, the prevalence of DMT2 was 34.6\%. This rate is higher than results from Egypt $(11.4 \%)$, Yemen (3.0\%), Iraq (10.2\%), and Algeria (8.5\%) [21]. The prevalence of DMT2 is also higher than the findings elsewhere in Saudi Arabia [5,12,13]. As Majmaah is a semi-urban area, this finding is unexpected; however, it may be explained by the fact that the city has experienced urbanization in the last few years. The establishment of Majmaah University and Sudair Industrial City has brought manpower from abroad and created new jobs and financial investment opportunities, resulting in lifestyle changes and the improved economic status of those in the population. having this in mind, the higher rate of DMT2 may be accounted for by the sample, which was taken from patients in PHCCs and not from the general population.

Our finding shows a significant relationship between DMT2 and age. Patients aged forty or older are more likely to have the disease compared with the younger age group $(p<0.001)$, which is congruent to the results of Alnozha et al. [5].

In the current study, females showed a slightly higher prevalence rate of the disease than males $(34.9 \%$ vs. $34.2 \%, p=0.9164)$. This finding is consistent with studies conducted in Saudi Arabia and Iran $[5,22]$ and is inconsistent with studies done in Saudi Arabia and France, where DMT2 was more prevalent in males [12,13,23].

DMT2 shows significant association with occupation $(p<0.001)[24,25]$. Business or private personnel showed higher prevalence of DMT2 (38.5\%) compared with government employees $(32 \%)$, students $(31.9 \%)$, and housewives (31.9\%).

In this study, we found a higher prevalence of DMT2 among married and divorced or widowed respondents compared with single respondents $(p<0.001)$. These findings are consistent with those of Murad et al. [23]. Marriage affects lifestyle; couples may increase food intake and become less active after marriage, leading to increased body weight and risk of developing the disease [23,25]. The prevalence of DMT2 does not show significant association with economic status [26,27]. Although 
the results of this study show a nonsignificant association between DMT2 and performing regular physical activities $(35.7 \%$ vs. $31.1 \%, p=0.336)$, the physical activities were shown in other studies to play a role in the development of diabetes [23,28-31].

Respondents who consumed fatty foods on a daily basis had a higher prevalence of DMT2 compared with those who did not [32]. Still, the relationship between DMT2 and consuming fatty foods on a daily basis is not significant.

Our study shows that tobacco smokers had DMT2 more than nonsmokers [2,33], but the relationship is not significant. This finding is inconsistent with that of Thelin et al. [2]. High levels of triglycerides, total cholesterol, and HDL showed significant associations with DMT2, in agreement with previous studies [2,34]. The relationships of these factors with DMT2 are consistent allover lipid profile studies. The variability of lipid panel components are noticed in this study as in the study of Alkaabba et al., where the percentages of total cholesterol were almost the same. The significance of total cholesterol as a risk factor is, however, different in this study [35], which shares the same results as an Iranian study [22].

The weight status in the current study shows significant association with DMT2, congruent to other studies where the prevalence of DMT2 was higher among obese subjects [36-38]. The prevalence of DMT2 tends to be higher among hypertensive patients, but in this study, we found that hypertension's relationship to DMT2 is insignificant. This finding is inconsistent with that of El-Hazmi et al. [39]. This might be explained by our method of taking blood pressure measurements; taking one reading in one setting is usually not conclusive of blood pressure status [17].

The study draws attention to the fact that DMT2 is no longer a disease of urban communities. More social studies need to be conducted to explore the root causes of this shift at the community level. Future researches should be done, in prospective longitudinal studies, in order to explore risk factors and their association or causation effects on the prevalence of DMT2 in smaller cities and how this reflects on the wider community.

\section{Conclusions}

The prevalence of type 2 diabetes mellitus among the semi-urban population of Saudi Arabia tested in this study is high. The disease is more prevalent among elderly respondents and is associated with obesity, high level of triglycerides, low HDL, and high total cholesterol. A comprehensive approach is needed to promote healthy lifestyles and avoid the burden of urbanization's negative health behaviors in communities of this size.

Funding: This research received no external funding.

Acknowledgments: The author would like to thank Deanship of Scientific Research at Majmaah University for supporting this work under Project Number No.R-1441-47. Also a great appreciation to Elsadig Yousif Mohamed, Sawsan Mustafa Abdalla, Mansour Alzahrani, Waqas Sami, Khalid Altohami Medani, Talal Alghamdi, and Fahad Alfhaid for their efforts in the project's success.

Conflicts of Interest: The authors declare no conflict of interest.

\section{References}

1. Lipscombe, L.L.; Hux, J.E. Trends in diabetes prevalence, incidence, and mortality in Ontario, Canada 1995-2005: A population-based study. Lancet 2007, 369, 750-756. [CrossRef]

2. Thelin, A.; Holmberg, S. Type 2 Diabetes and Lifestyle-A Prospective Population-Based Cohort Study among Rural Men. Int. J. Diabetes Clin. Res. 2014, 1, 2-5. [CrossRef]

3. World Health Organization-Department of Non-communicable Disease Surveillance. Definition, Diagnosis and Classification of Diabetes Mellitus and Its Complications: Report of a WHO Consultation; WHO: Geneva, Switzerland, 1999; Available online: https://apps.who.int/iris/bitstream/handle/10665/66040/WHO_NCD_ NCS_99.2.pdf (accessed on 17 October 2019).

4. Alqurashi, K.A.; Aljabri, K.S.; Bokhari, S.A. Prevalence of Diabetes mellitus in a Saudi community. Ann. Saudi Med. 2011, 31, 19-23. [CrossRef] [PubMed] 
5. Al-Nozha, M.M.; Al-Maatouq, M.A.; Al-Mazrou, Y.Y.; Al-Harthi, S.S.; Mohammed, R.F.; Arafah, A.M.Z.; Khan, N.B.; Al-Khadra, A.; Al-Marzouki, K.; Nouh, M.S.; et al. Diabetes Mellitus in Saudi Arabia. Saudi Med. J. 2004, 25, 1603-1610.

6. Shaw, J.E.; Sicree, R.A.; Zimmet, P.Z. Global estimates of the prevalence of diabetes for 2010 and 2030. Diabetes Res. Clin. Pract. 2010, 87, 4-14. [CrossRef]

7. International Diabetes Federation. IDF Diabetes Atlas 2003; International Diabetes Federation: Brussels, Belgia, 2003.

8. Zimmet, P.; Alberti, K.G.M.M.; Shaw, J. Global and societal-implications of the diabetes epidemic. Nature 2001, 414, 782-787. [CrossRef]

9. Badran, M.; Laher, I. Type II Diabetes Mellitus in Arabic-Speaking Countries. Int. J. Endocrinol. 2012, 2012, 90287. [CrossRef]

10. Pi-Sunyer, F.X. How effective are lifestyle changes in the prevention of type 2 diabetes mellitus? Nutr. Rev. 2007, 65, 101-110. [CrossRef]

11. Alqarni, S.S.M. A Review of Prevalence of Obesity in Saudi Arabia. J. Obes. Eat. Disord. 2016, 2, 2. [CrossRef]

12. Abou-Gamel, M.; Abdul-Nassir, M.; Ali Rajeh, A.; Makhdoom, A.; Surrati, A.; Kateb, A.; Albouq, F. The prevalence of diabetes mellitus among working personnel in the faculty of science, Taibah University, Almadinah Almunawwarah, KSA. J. Taibah Univ. Med. Sci. 2014, 9, 85-88. [CrossRef]

13. Al-Daghri, N.M.; Al-Attas, O.M.; Alokail, M.S.; Alkharfy, K.M.; Yousef, M.; Sabico, S.L.; Chrousos, G.P. Diabetes mellitus type 2 and other chronic non-communicable diseases in the central region, Saudi Arabia (Riyadh cohort 2): A decade of an epidemic. BMC Med. 2011, 9, 76. [CrossRef] [PubMed]

14. International Diabetes Federation. IDF Diabetes Atlas 2011, 5th ed.; International Diabetes Federation: Brussels, Belgium, 2011; Available online: http://www.idf.org/diabetesatlas (accessed on 30 December 2012).

15. Alhowaish, A.K. Economic costs of diabetes in Saudi Arabia. J. Fam. Community Med. 2013, $20,1-7$. [CrossRef] [PubMed]

16. Majmaah. Province of Majmaah. Emirate of Riyadh Region, Kingdom of Saudi Arabia. Available online: http://www.moi.gov.sa (accessed on 15 February 2015).

17. James, P.A.; Oparil, S.; Carter, B.L.; Cushman, W.C.; Dennison-Himmelfarb, C.; Handler, J.; Lackland, D.T.; LeFevre, M.L.; MacKenzie, T.D.; Ogedegbe, O.; et al. 2014 Evidence-Based Guideline for the Management of High Blood Pressure in Adults: Report From the Panel Members Appointed to the Eighth Joint National Committee (JNC 8). JAMA 2014, 311, 507-520. [CrossRef] [PubMed]

18. World Health Organization. Expert Committee on Physical Status: The Use and Interpretation of Anthropometry; Technical Report Series No. 854; WHO: Geneva, Switzerland, 1995.

19. American Diabetes Association. Standards of Medical Care in Diabetes. Diabetes Care 2014, 37 (Suppl. 1), S14-S80. [CrossRef] [PubMed]

20. National Institutes of Health; National Heart, Lung, and Blood Institute; National Cholesterol Education Program (US). Expert Panel on Detection, Evaluation, and Treatment of High Blood Cholesterol in Adults (Adult Treatment Panel III); Third Report of the National Cholesterol Education Program (NCEP); U.S. Department of Health and Human Services: Washington, DC, USA, 2002.

21. Chobanian, A.V.; Bakris, G.L.; Black, H.R.; Cushman, W.C.; Green, L.A.; Izzo, J.L., Jr.; Jones, D.W.; Materson, B.J.; Oparil, S.; Wright, J.T.; et al. The seventh report of the joint national committee on prevention, detection, evaluation, and treatment of high blood pressure: The JNC 7 Report. JAMA 2003, 289, 2560-2572. [CrossRef]

22. Azimi-Nezhad, M.; Ghayour-Mobarhan, M.; Parizadeh, M.R.; Safarian, M.; Esmaeili, H.; Parizadeh, S.M.; Khodaee, G.; Hosseini, J.; Abasalti, Z.; Hassankhani, B.; et al. Prevalence of type 2 diabetes mellitus in Iran and its relationship with gender, urbanisation, education, marital status and occupation. Singap. Med. J. 2008, 49, 571-576.

23. Murad, M.A.; Abdulmageed, S.S.; Iftikhar, R.; Sagga, B.K. Assessment of the Common Risk Factors Associated with Type 2 Diabetes Mellitus in Jeddah. Int. J. Endocrinol. 2014, 2014, 616145. [CrossRef]

24. Defay, R.; Delcourt, C.; Ranvier, M.; Lacroux, A.; Papoz, L.; POLA Study Group. Relationships between physical activity, obesity and diabetes mellitus in a French elderly population: The POLA study. Int. J. Obes. 2001, 25, 512-518. [CrossRef]

25. Musaiger, A.O.; Al-Awadi, A.A.; Al-Mannai, M.A. Lifestyle and social factors associated with obesity among the Bahraini adult population. Ecol. Food Nutr. 2000, 39, 121-133. [CrossRef] 
26. De Almeida, V.D.C.F.; Zanetti, M.L.; de Almeida, P.C.; Damasceno, M.M.C. Occupation and risk factors for type 2 diabetes: A study with health workers. Rev. Latino-Am. Enferm. 2011, 19, 476-484. [CrossRef]

27. Jeffery, R.W.; Rick, A.M. Cross-sectional and longitudinal associations between body mass index and marriage-related factors. Obes. Res. 2002, 10, 809-815. [CrossRef]

28. Lee, T.C.; Glynn, R.J.; Peña, J.M.; Paynter, N.P.; Conen, D.; Ridker, P.M.; Pradhan, A.D.; Buring, J.E.; Albert, M.A. Socioeconomic Status and Incident Type 2 Diabetes Mellitus: Data from the Women's Health Study. PLoS ONE 2011, 6, e27670. [CrossRef] [PubMed]

29. Ansari, R.M. Effect of Physical Activity and Obesity on Type 2 Diabetes in a Middle-Aged Population. J. Environ. Public Health 2009, 2009, 195285. [CrossRef] [PubMed]

30. Manson, J.E.; Nathan, D.M.; Krolewski, A.S.; Stampfer, M.J.; Willett, W.C.; Hennekens, C.H. A Prospective Study of Exercise and Incidence of Diabetes among US Male Physicians. JAMA 1992, 268, 63-67. [CrossRef] [PubMed]

31. Gill, J.M.; Cooper, A.R. Physical activity and prevention of type 2 diabetes mellitus. Sports Med. 2008, 38, 807-824. [CrossRef] [PubMed]

32. Ottoboni, A.; Ottoboni, F. Low-Fat Diet and Chronic Disease Prevention: The Women's Health Initiative and Its Reception. J. Am. Physicians Surg. 2007, 12, 10-13.

33. Carlsson, S.; Midthjell, K.; Grill, V. Smoking is associated with an increased risk of type 2 diabetes but a decreased risk of autoimmune diabetes in adults: An 11-year follow-up of incidence of diabetes in the Nord-Trondelag study. Diabetologia 2004, 47, 1953-1956. [CrossRef]

34. Beshara, A.; Cohen, E.; Goldberg, E.; Lilos, P.; Garty, M.; Krause, I. Triglyceride levels and risk of type 2 diabetes mellitus: A longitudinal large study. J. Investig. Med. 2016, 64, 383-387. [CrossRef]

35. Al-Kaabba, A.F.; Al-Hamdan, N.A.; El Tahir, A.; Abdalla, A.M.; Saeed, A.A.; Hamza, M.A. Prevalence and correlates of dyslipidemia among adults in Saudi Arabia: Results from a national survey. Open J. Endocr. Metab. Dis. 2012, 2, 89. [CrossRef]

36. Alqubali, H.F.; Albalawi, K.A.; Alswat, A.E.; Aljebreen, A.A.; Alotaibi, K.E.; Aljehani, A.S.; Almughamsi, R.A.; Hussain, A.M.; Albiek, H.F. Prevalence of Type 2 Diabetes Mellitus and Hypertension in Overweight and Obese People in Riyadh City, KSA 2017. Egypt. J. Hosp. Med. 2017, 69, 2614-2617. [CrossRef]

37. Mooradian, A.D. Dyslipidemia in type 2 diabetes mellitus. Nat. Rev. Endocrinol. 2009, 5, 150-159. [CrossRef] [PubMed]

38. Fatani, H.H.; Mira, S.A.; El-Zubier, A.G. Prevalence of Diabetes Mellitus in Rural Saudi Arabia. Diabetic Care 1987, 10, 180-183. [CrossRef] [PubMed]

39. El-Hazmi, M.A.; Warsy, A.S. Association of hypertension and non-insulin dependent diabetes mellitus in the Saudi population. Ann. Saudi Med. 2001, 21, 5-8. [CrossRef] [PubMed] 